\title{
Determinación del interferón-gamma en tuberculosis: Principios básicos y utilidad
}

\author{
Limberth Machado-Villarroel,*** Jesús Aníbal Acosta-Loya,* \\ Isaías Orozco-Andrade, * Gregorio Bravo-Rodríguez,* Diamanti Abraham Dimakis-Ramírez*
}

*Centro de Diagnóstico y Tratamiento Integral de la Tuberculosis de Servicios Médicos de la Frontera (CDTITB);

*Universidad Autónoma de Ciudad Juárez (UACJ).

Trabajo recibido: 10-VIII-2015; aceptado: 20-VIII-2015

\begin{abstract}
RESUMEN. La tuberculosis es una enfermedad transmisible distribuida globalmente con tasas de morbimortalidad elevadas. Resulta fundamental establecer un diagnóstico y tratamiento oportunos de la infección por tuberculosis. La reducción de tuberculosis latente reduce el riesgo de progresión a tuberculosis activa. La prueba cutánea de tuberculina es el método estándar de detección de infección por tuberculosis latente, empero presenta limitaciones en su desempeño, sensibilidad y especificidad; principalmente en individuos inmunocomprometidos y/o previamente vacunados con bacilo Calmette-Guérin. La prueba IGRA (del inglés interferon-gamma release assay, ensayo de liberación de interferón-gamma) fue diseñada para complementar el diagnóstico de infección latente por tuberculosis e incrementar la sensibilidad y especificidad, al cuantificar el interferón-gamma producido por linfocitos-T sensibilizados en respuesta al contacto con antígenos específicos de Mycobacterium tuberculosis. El IGRA aún es incapaz de discriminar una infección previa o actual por Mycobacterium tuberculosis, tampoco puede diferenciar entre infección latente por tuberculosis y tuberculosis activa. Existen dos pruebas IGRA disponibles comercialmente: QuantiFERON ${ }^{\circledR}$-TB Gold In-Tube y T-SPOT ${ }^{\circledR} T B$. El desempeño es superior en individuos inmunocompetentes $>5$ años de edad. Sin embargo, la eficacia clínica resulta afectada en individuos inmunodeprimidos, debido a una síntesis reducida y fluctuante de interferón-gamma en dicho grupo de pacientes. Factores como la inmunosupresión contribuyen a obtener resultados indeterminados, lo cual debe considerarse al momento de interpretar la prueba.
\end{abstract}

Palabras clave: Ensayos de liberación de interferón-gamma, interferón-gamma, linfocitos-T, tuberculosis latente.

ABSTRACT. Tuberculosis is a globally distributed communicable disease with high rates of morbimortality. It is fundamental to establish an opportune diagnosis and treatment of latent tuberculosis infection, reducing the risk of progression to active tuberculosis. Tuberculin skin test is the standard screening method for latent tuberculosis infection, however, it presents limitations in its performance, low sensitivity and specificity, mostly in immunocompromised individuals and/or previously vaccinated with Bacillus Calmette-Guérin. IGRA (Interferon-Gamma Release Assay) test was designed to improve latent tuberculosis infection diagnosis and to increase sensitivity and specificity by means of quantifying interferon-gamma produced by sensitized T lymphocytes in response to contact with specific Mycobacterium tuberculosis antigens. IGRA test is still incapable to discriminate neither previous from current Mycobacterium tuberculosis infection, nor differentiate between latent tuberculosis infection and active tuberculosis. Two commercially available IGRA tests exist: QuantiFERON ${ }^{\circledR}$-TB Gold In-Tube and T-SPOT ${ }^{\circledR}$. TB. Performance is superior in immunocompetent individuals $>5$ years old. Clinical efficacy is affected in immunocompromised individuals owing to a reduced and fluctuant interferon-gamma synthesis in such group of patients. Factors such as immunosuppression contribute to obtain indeterminate results, which must be taken into account when interpreting the test.

Key words: Interferon-gamma release assays, interferon-gamma, latent tuberculosis, T-lymphocytes.
Abreviaturas:
MTB: Mycobacterium tuberculosis
BCG: Bacilo Calmette-Guérin
TB: Tuberculosis
TBP: Tuberculosis pulmonar
TBPA: Tuberculosis pulmonar activa
TBEP: Tuberculosis extrapulmonar
ITBL: Infección por tuberculosis latente
TBA: Tuberculosis activa
VIH: Virus de la inmunodeficiencia humana
IFN- $\gamma$ : Interferón-gamma
PCT: Prueba cutánea de tuberculina
IGRA: Interferon-gamma release assay
QFT-GIT: QuantiFERON ${ }^{\circledR}$-TB Gold In-Tube
ELISA: Enzyme-linked immunosorbent assay
ESAT-6: Early secretory antigenic target-6
CFP-10: Culture filtrate protein-10
IP-10: Interferon-gamma-induced protein-10
VPN: Valor predictivo negativo
PCR: Proteína $\mathrm{C}$ reactiva
SIDA: Síndrome de inmunodeficiencia adquirida 


\section{ANTECEDENTES}

El MTB es el agente etiológico de la TB, una de las enfermedades transmisibles con mayor mortalidad a nivel global. Tan sólo en el año 2013 alrededor de 9 millones de personas desarrollaron TB, 1.1 millones de los casos se diagnosticaron en individuos infectados con $\mathrm{VIH}$, asimismo se registraron 1.5 millones de defunciones y 360,000 de los sujetos eran $\mathrm{VIH}^{+} .{ }^{1} \mathrm{En}$ México se registran anualmente cerca de 15,000 casos nuevos de TBP y alrededor de 2,000 defunciones por dicha causa, lo cual representa una pérdida sustancial de años potenciales de vida saludable, esto implica un obstáculo para el desarrollo socioeconómico del país puesto que el promedio de edad de muerte por TB es de 54 años. $^{2}$ En México, las enfermedades asociadas con mayor frecuencia a la TB son: diabetes mellitus (19\%), desnutrición (10\%), VIH/SIDA (6\%) y alcoholismo (4\%). Las enfermedades antes mencionadas colocan a la población afectada en una situación de vulnerabilidad inmunológica y actúan simultáneamente como determinantes sociales de la TB. ${ }^{3}$

Uno de los mecanismos principales que están implicados en la patogenia de la enfermedad es la respuesta inmunitaria celular donde participan los linfocitos-T, la cual brinda protección frente a patógenos intracelulares como MTB. Las células responden a los antígenos proteicos de los microorganismos fagocitados, presentados por los macrófagos como péptidos asociados a moléculas de clase I del complejo mayor de histocompatibilidad, lo que contribuye a su diferenciación a células efectoras $T_{h} 1$ bajo la influencia de la interleucina-12, estas células $\mathrm{T}_{\mathrm{h}} 1$ secretan IFN- $\gamma$, el cual estimula la producción de diversas sustancias microbicidas. ${ }^{4}$ En la mayoría de los casos, el MTB producirá ITBL debido a una eficaz activación de los macrófagos estimulados por células $\mathrm{T}$, lo que propicia la formación de granulomas alrededor de los microorganismos y por tanto focaliza y evita su diseminación. Sin embargo, la respuesta inflamatoria granulomatosa está asociada a deterioro funcional debido a la necrosis y fibrosis tisulares acompañantes. Sólo una minoría de los sujetos expuestos (probablemente < 10\%) desarrollan TBA.

Durante el siglo pasado se implementó la utilización de la PCT para cuantificar la exposición a MTB, no obstante, dicha prueba presenta limitaciones en su desempeño, sensibilidad y especificidad. ${ }^{5}$ Lo anterior llevó a la necesidad de diseñar otros métodos que mejoraran la sensibilidad y la especificidad; tal es el caso de la prueba IGRA, misma que es capaz de detectar una respuesta inmunitaria específica a MTB por parte de linfocitos-T sensibilizados del paciente, esto al cuantificar la producción de IFN- $\gamma$ mediante la técnica ELISA o ELISpot.

En diversos estudios se ha documentado que el IGRA puede mejorar la especificidad para detectar ITBL al ser comparado con la PCT, esto radica en que contiene antígenos no expresados en el BCG, permitiendo distinguir entre una PCT positiva debida a vacunación BCG y una PCT positiva causada por sensibilización a MTB. Sin embargo, tanto la PCT como el IGRA son incapaces de distinguir entre una infección previa o actual con MTB, así como tampoco pueden diferenciar entre TBA e ITBL. ${ }^{6}$

\section{DIAGNÓSTICO DE ITBL}

El término ITBL se refiere a la presencia de MTB en el organismo sin signos y síntomas, o evidencia radiográfica o bacteriológica de TB. Alrededor del $30 \%$ de las personas expuestas a MTB desarrollan una ITBL, con un riesgo de $5-10 \%$ de progresión a TBA. ${ }^{7}$ El riesgo de desarrollar TB es más elevado en individuos con alteraciones de la inmunidad celular, sobre todo aquellos infectados con $\mathrm{VIH}$; por lo tanto, la evolución epidémica de dicha infección viral ha originado la distribución global de TB en las últimas décadas.1,7 Asimismo, están en riesgo los receptores de órganos trasplantados, pacientes bajo tratamiento con antagonistas del factor de necrosis tumoral y pacientes con insuficiencia renal crónica. $^{8}$

Es bien sabido que, el diagnóstico de la ITBL se efectúa de forma indirecta a través de la detección de una respuesta inmunitaria celular específica frente a antígenos de la micobacteria en ausencia de datos clínicos sugestivos, en contraste con la TBA, la cual precisa la identificación bacteriana del bacilo de Koch así como la presencia de manifestaciones clínicas inherentes a la entidad nosológica, aunque en algunos casos el cuadro puede ser subclínico. ${ }^{1}$ Por tanto, la existencia de una respuesta inmunitaria específica constituye una referencia útil para dilucidar el contacto previo o concurrente con antígenos de la micobacteria.

Actualmente, existen dos tipos de ensayos clínicos para efectuar el diagnóstico de la ITBL: la PCT y el IGRA. La PCT constituye un método in vivo, mientras que el IGRA consiste en una modalidad ex vivo basada en la detección de una respuesta inmunitaria específica frente a MTB, esto se lleva a cabo cuantificando la síntesis de citocinas por parte de los linfocitos- $T_{h} 1$ luego de haber sido estimulados por antígenos específicos de la micobacteria. ${ }^{9}$ Anteriormente, el diagnóstico de la ITBL radicaba de forma exclusiva en el empleo de la PCT, la cual sufre de una sensibilidad reducida en 
pacientes inmunocomprometidos así como de una pobre especificidad asociada a individuos con vacunación de BCG previa. ${ }^{5}$ En contraste, el IGRA es una prueba sanguínea desarrollada inicialmente para fortalecer el poder diagnóstico al ser capaz de cuantificar la respuesta inmunitaria celular frente a antígenos específicos de MTB, por ende, una prueba positiva constituye un diagnóstico de ITBL aun en ausencia de evidencia clínica y/o radiológica ${ }^{10}$ y brinda una especificidad del $98-100 \%$ y una sensibilidad del $70-90 \% .{ }^{11}$ No obstante, cabe mencionar que el IGRA no cuenta con la sensibilidad y especificidad suficientes para confirmar o descartar la TBA.,12

\section{LINFOCITOS-T Y PRUEBAS IGRA}

El ensayo IGRA consiste en una prueba sanguínea que valora la respuesta inmunitaria frente a MTB, creada originalmente para ser más específica y sensible en el diagnóstico de TB, sobre todo en pacientes previamente expuestos al BCG por motivo de vacunación o terapia oncológica, así como en personas expuestas a la mayoría de micobacterias no tuberculosas (con excepción de M. kansasii, M. szulgai, y M. marinum). ${ }^{13}$ El ensayo se logra al detectar el IFN- $\gamma$ producido por linfocitos-T en respuesta a antígenos específicos de MTB. Las dos modalidades de la prueba IGRA disponibles comercialmente son: T-SPOT ${ }^{\circledR}$.TB (Oxford Immunotec, Abingdon, Reino Unido) y QFT-GIT (Qiagen, Hilden, Alemania). Los antígenos específicos contenidos en la prueba T-SPOT ${ }^{\circledR}$.TB son ESAT- 6 y CFP-10, mientras que en la prueba QFT-GIT además de los antígenos ya mencionados utiliza TB 7.7.7.14

Hay estudios que sugieren que la cifra de células $T$ efectoras en conjunto con la cantidad de IFN- $\gamma$ liberada representan un predictor cuantitativo más fidedigno de infecciosidad en comparación con un simple resultado positivo del IGRA, ${ }^{10}$ pues se ha encontrado una correlación entre el grado de exposición y el número de células T activadas por CFP-10/ESAT-6 en la prueba TSPOT ${ }^{\circledR}$.TB y la cantidad de IFN- $\gamma$ liberada en adultos. ${ }^{15}$ Un conteo elevado de células CD4+ está asociado con mayor cantidad de IFN- $\gamma$ en el transcurso del tiempo, indicativo de la persistencia de respuestas inmunitarias eficaces que podría tener implicaciones pronósticas. ${ }^{16}$ Mencionamos las características técnicas para llevar a cabo las pruebas (figura 1).

En el caso de T-SPOT ${ }^{\circledR}$.TB idealmente se requieren 6-8 $\mathrm{mL}$ de sangre venosa, recolectados en una sola alícuota diseñada para la preparación de células mononucleares. La sangre deberá llegar lo antes posible al laboratorio, se obtienen células a través de pasos sucesivos de centrifugado y lavados, posteriormente se contabilizan. Acto seguido, se colocan células mononucleares junto con antígenos específicos de MTB en 2 pocillos de una placa de microtitulación (el panel A contiene ESAT-6, mientras que el panel B contiene CFP-10) cubiertos con anticuerpos específicos contra IFN- $\gamma, 1$ pocillo sin antígenos (control nulo), así como 1 pocillo con fitohemaglutinina (control positivo). Las placas se incuban a $37^{\circ} \mathrm{C}$ durante la noche y, posteriormente, se lleva a cabo el ensayo con reactivos adicionales para visualizar finalmente el número de células $T$ específicas productoras de IFN- $\gamma$. Dichas células son enumeradas en comparación con los controles nulo y positivo al emplear un instrumento de lectura ELISpot, lo cual requiere la cuantificación de manchas obtenidas. Los resultados se reportan como positivos (panel A-control nulo y/o panel B-control nulo $\geq 8$ manchas), negativo (panel A-control nulo y panel B-control nulo $\leq 4$ manchas), limítrofe (panel A o panel B con 5-7 manchas) o indeterminado (panel $A$ o panel $B \leq 5$ manchas), en cuyo caso deberá repetirse el ensayo. ${ }^{13,14}$ Las instrucciones para el QFT-GIT se encuentran en el paquete incluido. La prueba se lleva a cabo en dos etapas. Primero, se requieren $3 \mathrm{~mL}$ de sangre venosa colocados en tres alícuotas heparinizadas de $1 \mathrm{~mL}$ : control nulo (realiza ajustes según los antecedentes del paciente, efectos de anticuerpos heterófilos, o IFN- $\gamma$ inespecífico en muestras sanguíneas), tubo con antígenos TB, y tubo con mitógeno (puede actuar como control positivo de cada espécimen empleado); después se incuban a $37{ }^{\circ} \mathrm{C}$ con antígenos de prueba por $16-24$ horas. En el segundo paso, los tubos se centrifugan, se remueve el plasma y se mide la cantidad de IFN- $\gamma(\mathrm{UI} / \mathrm{mL})$ mediante ELISA, para lo anterior se requiere sustraer la cantidad de IFN- $\gamma$ del nivel de IFN- $\gamma$ del tubo con antígenos TB y mitógeno (en caso de ser utilizado). ${ }^{12,14}$ Los resultados de la prueba pueden ser calculados empleando un software proporcionado por el fabricante. El resultado final es reportado como positivo cuando la producción de IFN- $\gamma$ en el tubo con antígenos TB es significativamente superior a la cifra de IFN- $\gamma$ en el control nulo, negativo, o indeterminado cuando la respuesta al mitógeno es baja $(<0.5 \mathrm{UI} / \mathrm{mL})$ y en asociación a una respuesta negativa en una muestra sanguínea frente a los antígenos TB. Los resultados indeterminados no son clínicamente interpretables y necesitan repetirse..$^{17}$

\section{ESCENARIO CLÍNICO EN PACIENTES INMUNOCOMPETENTES}

Hasta la fecha, el ensayo IGRA no ha mostrado una capacidad de detección óptima de TBA en pacientes 
1. Presentación del antígeno

(ESAT-6, CFP-10, TB 7.7)

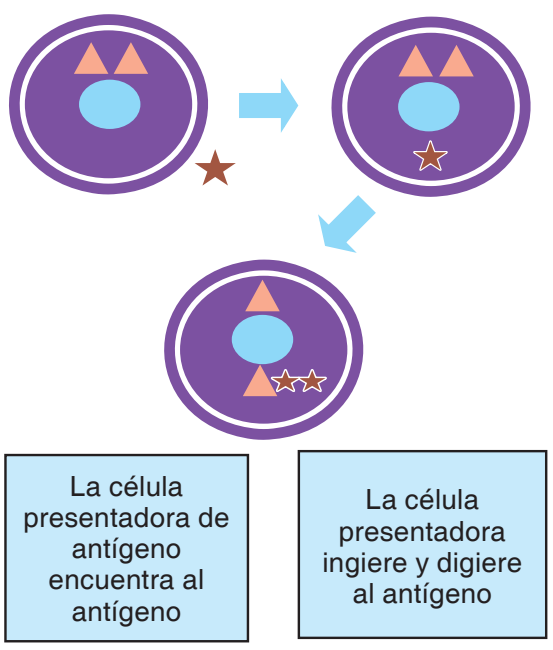

2. Producción de citocina específica (IFN- $\gamma$ )

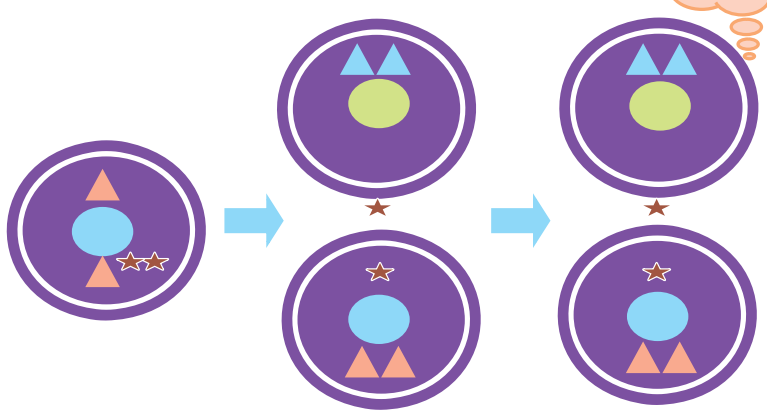

IFN- $\gamma$

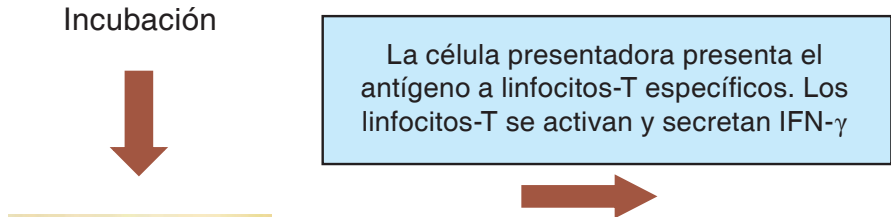

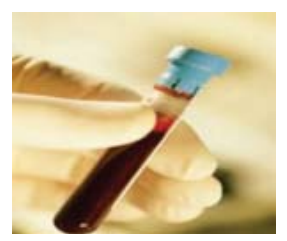

3. Cuantificación de citocina

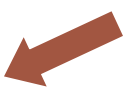

Utilizando células mononucleares de sangre periférica y ELISpot
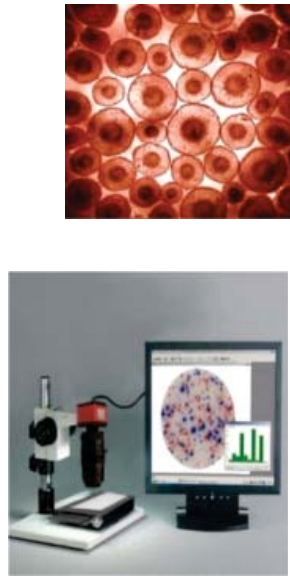

Si el antígeno es específico a TB, sólo se activarán linfocitos-T específicos a TB y secretarán IFN- $\gamma$

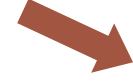

Utilizando plasma y ELISA
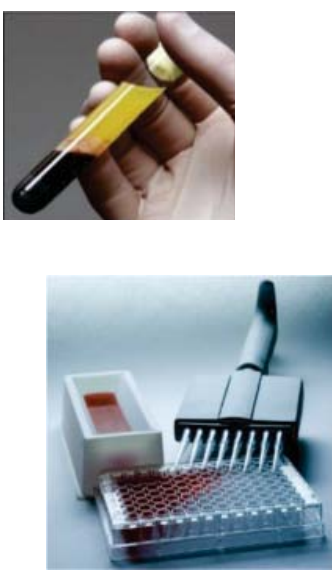

Figura 1.

Modificado de: Principios inmunológicos de los ensayos de liberación de interferón- $\gamma$ disponibles comercialmente. Traducido y adaptado con permiso de BMJ Publishing Group Limited: Arch Dis Child [How to use: interferon- $\gamma$ release assays for tuberculosis. Pollock L, Roy RB, Kampmann B. 98(3):99105], Derechos Reservados (2015). inmunocompetentes. ${ }^{11}$ No obstante, debido al VPN elevado del IGRA, en sujetos inmunocompetentes sin compromiso de liberación de IFN- $\gamma$ se puede considerar como predictor confiable de mínima progresión a enfermedad activa. ${ }^{9}$

Dagnew et al. comprobaron en un estudio que no existía una diferencia considerable en las tasas de resultados positivos entre la prueba QFT-GIT en un grupo de individuos previamente vacunados con BCG y el grupo que no presentaba dicho antecedente $(47.9 \%$ vs. $40.7 \%$ ); igualmente fue capaz de demostrar una correlación sólida $(91.6 \%)$ entre una PCT con induración $\geq 10 \mathrm{~mm}$ y un QFT-GIT positivo en adultos jóvenes en buen estado de salud. ${ }^{15,18}$ 
En pacientes pediátricos menores de 5 años de edad existe una producción disminuida de IFN- $\gamma$ en respuesta al contacto con antígenos específicos de MTB, se presume que esta característica se encuentra asociada con la inmadurez inmunológica en dicha etapa del desarrollo, que podría generar dificultades en la interpretación del desempeño de la prueba IGRA al generar resultados falsos negativos. ${ }^{19}$ Por tanto, debido al elevado VPN, las pruebas IGRA son promisorias principalmente en personas inmunocompetentes mayores a 5 años de edad, quienes habitan en un medio con baja prevalencia de TB, como es el caso de los países desarrollados. ${ }^{20}$ Por otro lado, Kamiya et al. demostraron que en pacientes de edad avanzada con comorbilidades que implican una mayor síntesis de IFN- $\gamma$, la prueba QFT-GIT podría tener una precisión reducida, ya que en estudios se ha demostrado que la proporción de pacientes con otras enfermedades y resultados falsos positivos era mayor en personas ancianas, por lo que debería prestarse especial atención en la evaluación clínica de resultados positivos en dicho grupo de población. ${ }^{21}$

\section{ESCENARIO CLÍNICO EN PACIENTES INMUNODEPRIMIDOS}

En general, el riesgo de desarrollar TB en los sujetos inmunocomprometidos está influenciado por los mecanismos inmunológicos subyacentes, así como la duración y relación temporal de la exposición previa a MTB. ${ }^{2}$ Las personas con inmunodeficiencias se encuentran particularmente vulnerables en términos de progresión a TBA, situación observada con mayor frecuencia en individuos infectados con $\mathrm{VIH}$. Cabe mencionar que los resultados de pruebas inmunodiagnósticas pueden variar según la naturaleza y grado de la inmunodeficiencia, por lo que no se consideran predictores confiables del riesgo para contraer TB entre grupos diversos de pacientes inmunocomprometidos. ${ }^{8}$

Como se ha mencionado anteriormente, el desempeño del IGRA está considerablemente limitado en pacientes quienes por diversos motivos se encuentren inmunodeprimidos (padecimientos oncológicos, terapia inmunomoduladora en caso de patología autoinmune, receptores de órganos trasplantados, diabetes mellitus, etc.) a causa de los resultados indeterminados prevalentes en dicha población. ${ }^{21,22}$

Varios artículos han evidenciado la reducida información disponible actualmente en cuestión del VPN de Ios IGRA en huéspedes inmunocomprometidos, esto aunado al riesgo elevado existente de infección con TB así como de progresión a TBA; por lo contrario, ha llevado a emitir la recomendación de instaurar terapia antibiótica profiláctica con isoniazida, sobre todo en pacientes jóvenes inmunodeprimidos, sin importar los resultados subsecuentes de dichas pruebas. ${ }^{22}$

En resumen, las pruebas IGRA no son capaces de identificar acertadamente a los pacientes inmunocomprometidos con riesgo de padecer TB, lo cual hace necesario desarrollar de forma urgente mejores técnicas y marcadores biológicos para seleccionar específicamente a los individuos inmunocomprometidos con mayor riesgo de desarrollar la infección en un futuro, con el objetivo de instaurar una quimioterapia profiláctica anticipada y efectiva. ${ }^{8}$

\section{CORRELACIÓN CLÍNICA DEL IFN- $\gamma$ EN PACIENTES CON TBA, ITBL, VIH Y TB}

El IFN- $\gamma$ constituye una citocina potente fundamental en la mediación de la respuesta inmunitaria adaptativa frente a MTB, por ello al confirmar la presencia de una respuesta específica frente a antígenos de la micobacteria es posible evidenciar el contacto previo o actual con el agente patógeno; ${ }^{10}$ aunque en un contexto clínico dicha respuesta no proporciona evidencia directa de bacilos viables, por lo que no se considera un indicador específico de un riesgo incrementado de progresión a TBA. ${ }^{7,9,12}$

$\mathrm{Ha}$ incrementado la evidencia qua valida la hipótesis de la superioridad del IGRA sobre la PCT en el diagnóstico de la infección con MTB; no obstante, persiste la interrogante con respecto a la habilidad de dicha prueba inmunodiagnóstica para identificar con precisión a los sujetos expuestos con mayor riesgo de desarrollar TBA. ${ }^{23}$

En un estudio Lee et al. verificaron la reducción en los niveles de IFN- $\gamma$ en la mayoría de los pacientes tras haber concluido exitosamente la terapia antituberculosa, lo que influye en la interpretación de los resultados seriales del IGRA en sujetos bajo tratamiento farmacológico ya que puede presentarse la reversión de dicha prueba hasta en un $50 \%$ de los casos. ${ }^{24}$

Cuando el IGRA se emplea en pacientes inmunocompetentes con ITBL ofrece varias ventajas en comparación con la PCT: los resultados son numéricos, y por tanto, sujetos en menor medida a la parcialidad del examinador; no requiere de una visita de seguimiento para efectuar la lectura de los resultados; asimismo, utiliza antígenos específicos a MTB no presentes en el $B C G$, por lo que no resulta afectado por la vacunación BCG previa. ${ }^{25}$

Los bacilos son capaces de sobrevivir durante muchos años y reactivarse en cualquier momento, sobre todo en huéspedes que cursan con alguna inmunodeficiencia como la que genera el $\mathrm{VIH} .{ }^{26}$ Está comprobado mediante análisis genéticos que en individuos $\mathrm{VIH}^{+}$ 
en quienes previamente se desarrolló una respuesta inmunitaria específica con síntesis de IFN- $\gamma$ frente a otro estímulo antigénico distinto de MTB poseen aún un riesgo reducido de TB subsecuente. ${ }^{26}$ En pacientes $\mathrm{VIH}^{+}$se registran valores fluctuantes de IFN- $\gamma$, motivo por el cual se recomienda repetir la prueba con cierta periodicidad, incluso, en casos selectos, no brindar terapia profiláctica sin antes analizar en conjunto el escenario clínico del sujeto en particular. ${ }^{16}$ Algunos autores han emitido la recomendación de implementar la sensibilidad de la prueba IGRA obteniendo al menos un resultado positivo en combinación con la PCT, esto resultaría útil clínicamente para identificar a pacientes $\mathrm{VIH}^{+}$con ITBL quienes se beneficiarían del tratamiento preventivo. ${ }^{27} \mathrm{La}$ evidencia sugiere que los IGRA poseen ventajas específicas en ciertas poblaciones de pacientes inmunocomprometidos y bajo situaciones particulares. Por ejemplo, T-SPOT ${ }^{\circledR}$.TB resulta menos afectado por un recuento bajo de células $\mathrm{CD}^{+}$en personas infectadas con VIH en comparación con la PCT y QFT-GIT. De igual forma, la prueba QFT-GIT mantiene una sensibilidad considerable en pacientes con diálisis en comparación con la PCT y probablemente con T-SPOT ${ }^{\circledR}$. TB. $^{25}$

\section{RESULTADOS INDETERMINADOS EN LA PRUEBA IGRA}

Un metaanálisis del año 2011 reportó la presencia de resultados falsos negativos o indeterminados hasta en un $20 \%$ de los pacientes con TBA con el empleo del IGRA más utilizado, es decir, QFT-GIT; ${ }^{28}$ se han propuesto diversas causas para un resultado indeterminado en dicha prueba, la inmunosupresión (por ejemplo, infecciones avanzadas con VIH y tratamiento con fármacos inmunosupresores) es la más factible y mejor documentada. De forma adicional influyen también otros factores como la edad (menor a 5 años), nefropatía terminal, edad avanzada (mayor a 70 años), insuficiencia/deficiencia de vitamina D, infecciones helmínticas, paludismo y enfermedades virales simultáneas. ${ }^{28,29}$ Por tanto, resulta evidente la limitación de su utilidad en estas circunstancias clínicas.

Estudios efectuados, tanto en ratones como en seres humanos han evidenciado el efecto negativo del tabaquismo en asociación con una producción reducida de IFN- $\gamma$ posterior a un estímulo antigénico con la concomitante estimulación de linfocitos-T, hallazgo que a su vez sugiere una alteración en el desempeño de pruebas inmunodiagnósticas como el IGRA. 28,29

Una revisión sistemática de estudios referentes al IGRA en pacientes pediátricos reveló tasas promedio de resultados indeterminados en un 6.5 y $3.5 \%$, para el QFT-GIT y T-SPOT ${ }^{\circledR} . T B$, respectivamente. ${ }^{7}$ En tanto otros estudios reportaron tasas más elevadas de resultados indeterminados principalmente en asociación con una corta edad, coinfección helmíntica e inmunosupresión, sin embargo, no se demostró mediante metaanálisis una correlación trascendental con esos factores de riesgo específicos. Asimismo, en dichos estudios ha sido posible demostrar que el T-SPOT ${ }^{\circledR} . T B$ mostró una menor cantidad de resultados indeterminados asociados a factores como linfocitopenia y corta edad, en comparación con el QFT-GIT.7,12

Finalmente, en un estudio se ha identificado un alelo específico del antígeno leucocitario humano clase II caracterizado por varios factores que posiblemente predispongan a una falsa negatividad del IGRA en la TBPA. ${ }^{30}$

\section{SEGUIMIENTO Y EVOLUCIÓN DE LA ENFERMEDAD Y CORRELACIÓN CON IGRA}

Los factores inmunológicos innatos y adaptativos del huésped son determinantes del curso de la enfermedad, los cuales dan como resultado cuatro posibles escenarios: infección primaria por TB, ITBL, reactivación posterior o eliminación del bacilo. ${ }^{6,9}$

Resulta fundamental hacer énfasis en la considerable prevalencia de ITBL, razón para requerir de una estrategia adecuada de seguimiento en dicho grupo de pacientes en mira de reducir al máximo la tasa de reactivación y progresión a TBA, con especial interés en evitar las formas diseminadas de la patología ya que comprenden una gran carga de morbimortalidad..$^{8,18}$

Después de 2 años, la tasa de progresión de una prueba IGRA positiva a TBA supera aquélla de la PCT (8-15\% vs. 2-3\%); sin embargo, debido a su elevado VPN reduce y hace pobre la asociación con un riesgo incrementado de progresión, ${ }^{9}$ simultáneamente constituye un indicador clave para los programas de control de TB, esto al limitar la terapia a los contactos de sujetos con pruebas positivas. ${ }^{11}$

Hasta el momento, las pruebas IGRA han demostrado superioridad en cuanto al valor predictivo positivo frente a la PCT, las cuales se ejecutan con fines de valoración para progresión, sobre todo en el escenario clínico de rastreo de contactos en países con baja incidencia. ${ }^{9}$ La información más reciente indica que la detección y el manejo de ITBL son un elemento clave en el control de TB, especialmente en países con cifras de incidencia reducidas; por otro lado, en naciones con una incidencia elevada de TB el cribado de ITBL cobra particular interés en grupos de alto riesgo, tal es el caso de aquellos pacientes infectados con $\mathrm{VIH} .{ }^{14}$ Asimismo, 
existe evidencia sugestiva de mejorar la detección de TBA y, por ende, la capacidad discriminativa entre ITBL y TBA al emplear en combinación la prueba IGRA y la PCT. ${ }^{31}$ La reproducibilidad del IGRA tiene importancia debido a una variación serial de la respuesta de células $T$ en un mismo sujeto. Dichas pruebas son altamente dinámicas, por lo que una prueba débilmente positiva tiende a variar, lo que ha llevado al reporte de conversiones, reversiones e incluso variaciones inespecíficas. ${ }^{10,11}$ El significado clínico de esta variación de la conversión y/o reversión del IGRA no es clara, aún es complicado establecer un punto de corte óptimo entre una infección verdadera y una simple variabilidad biológica. Hay estudios que indican que se precisa de una exposición continua frente a MTB para mantener una respuesta IGRA elevada en contactos de casos de TB. ${ }^{32}$ Se ha demostrado en algunos estudios que los niveles de IFN- $\gamma$ no se reducen significativamente aun posterior a la administración de antifímicos de forma profiláctica, razón para no recomendar la utilización del IGRA con fines de monitorización de la terapia preventiva en casos de ITBL. ${ }^{32,33}$ Por otro lado, generalmente el manejo quimioprofiláctico en contactos de casos de TB ha llevado a una reducción en los niveles de IFN- $\gamma$, empero sólo en una pequeña proporción se alcanzó la reversión. ${ }^{34}$ Existe información obtenida de varios estudios que revela una reducción en los niveles de IFN- $\gamma$ subsecuente a un tratamiento antifímico exitoso en pacientes con TBA, aunque en menos del $50 \%$ se logró una reversión, este fenómeno ha sido observado particularmente en individuos con valores basales bajos de IFN- $\gamma$, PCR, así como fiebre al momento del diagnóstico de TBA. ${ }^{24}$

\section{NORMATIVIDAD ACTUAL DEL IGRA EN MÉXICO}

Las pruebas IGRA poseen buena especificidad, sobre todo en pacientes con previa vacunación $B C G$, como es el caso de la población mexicana. ${ }^{15,18,35}$ No obstante, en un país con incidencia elevada de TB y bajos ingresos per capita como México, el uso del IGRA está sujeto a limitaciones bajo ciertas circunstancias, lo cual podría hacerlo incluso inferior a la PCT, razón por la cual aún se favorece el empleo de esta última. ${ }^{36,37}$ De igual manera hay que considerar aspectos adicionales en relación con los costos, disponibilidad clínica en el sector salud, aceptabilidad de parte del paciente, facilidad de distribución y almacenamiento.

Algunos investigadores sugieren que el uso conjunto de un método con gran especificidad como el IGRA y la PCT resultaría útil para los médicos clínicos en un entorno como el nuestro al incrementar la sensibilidad diagnóstica de ITBL. ${ }^{18,27}$ Las pruebas IGRA podrían posiblemente tener utilidad para monitorizar los estándares de salud en situaciones clínicas en las cuales se sospeche el contacto con pacientes infectados por MTB o material potencialmente infeccioso. ${ }^{38}$

El primer nivel de atención en salud debe ser capaz de asumir un papel fundamental en la promoción del diagnóstico temprano, tanto de la TBA como de la ITBL a través de un enfoque sistemático de detección de TB, principalmente en los grupos de alto riesgo. ${ }^{8}$ No obstante, los recursos disponibles para efectuar las pruebas necesarias se hallan limitados, lo cual implica una consecuente variación en el grado de implementación del IGRA. Uno de los factores que limitan la aplicación es la escasa evidencia del poder pronóstico en pacientes pediátricos y sujetos inmunocomprometidos así como resultados falsos negativos, por tanto se recomienda el uso conjunto de PCT e IGRA en niños y pacientes $\mathrm{VIH}^{+}$ con cifras de células CD4 ${ }^{+}$menores a 200 células/ $\mu \mathrm{L} .^{13}$

Aún no está justificado el empleo del IGRA con fines diagnósticos de TBA puesto que se requiere de una mayor sensibilidad por parte de la prueba. En una población altamente móvil como la observada en las ciudades pertenecientes a la franja fronteriza, un protocolo de detección basado en la combinación del IGRA con la examinación radiológica del tórax resulta efectiva en la diferenciación entre TBA e ITBL. ${ }^{31}$

En México aún se emplea la PCT como estándar para el diagnóstico de TB, misma que determina la exposición previa a MTB. La PCT consiste en la inyección intradérmica de 5 unidades de derivado proteínico purificado en la cara lateral del antebrazo, contralateral a la vacuna BCG; la lectura de la reacción dérmica se realiza 48-72 horas después y una prueba se define como positiva en relación con el diámetro de la induración: $\geq 5 \mathrm{~mm}$ en pacientes inmunocomprometidos y en contactos recientes de casos con TBA, $\geq 10 \mathrm{~mm}$ en otros grupos de riesgo (pacientes oncológicos, desnutridos, entre otros) y $\geq 15 \mathrm{~mm}$ en grupos de bajo riesgo. En caso de obtener un resultado positivo se procede a descartar TBA o ITBL. ${ }^{2}$

\section{FUTURAS DIRECCIONES Y UTILIDADES DEL IGRA}

Una amplia gama de nuevos marcadores biológicos, que incluye pruebas IGRA de próxima generación, está en proceso de evaluación para correlacionar las respuestas basales con el desenlace clínico. Se desarrollan y justifican algoritmos diagnósticos basados en la evidencia así como un análisis financiero de los recursos sanitarios para estimar la utilidad clínica y el costo-beneficio, tanto de las pruebas IGRA existentes como las consecuentes en los contextos de sospecha de TB y pacientes de edad avanzada, ya que en estos 
últimos el diagnóstico de TB suele omitirse y conlleva un desenlace fatal..$^{9,21}$

Para evaluar apropiadamente la eficacia del IGRA en el diagnóstico de TBEP aún resulta necesario efectuar estudios de mayor amplitud. ${ }^{39}$

Los valores predictivos del IGRA están determinados por la prevalencia de la TBP y TBEP en una población, lo cual representa un factor clave para entender el impacto que adquiere dicho ensayo inmunodiagnóstico como medida preventiva en TB. ${ }^{1,6,8}$

Otras citocinas como la interleucina-2 y la IP-10 se encuentran en estudio como medidas viables de optimización con fines predictivos del ensayo inmunodiagnóstico de TB en grupos de alto riesgo; la citometría de flujo se encuentra ajustada particularmente en la definición de ciertas propiedades funcionales o inmunofenotípicas de mayor complejidad sugerentes de progresión a TBA. ${ }^{9}$

Debido a la buena especificidad y a las ventajas logísticas que proporciona, se recomienda la utilización del IGRA en países con una incidencia de TB reducida y buena disponibilidad de recursos humanos y materiales. Muchos autores han sugerido implementar la prueba IGRA con fines de detección de ITBL en viajeros a países altamente endémicos de TB quienes retornan 8 semanas después a su país de origen, principalmente cuando existe la sospecha de una potencial exposición al haber estado involucrados en actividades propias del sector salud. . ${ }^{36-38,40}$ Prácticamente todas las guías internacionales que emiten recomendaciones de efectuar pruebas de cribado en inmigrantes incorporan el uso del IGRA. ${ }^{14}$

Resulta primordial implementar el poder pronóstico del IGRA mediante la reducción del número necesario a tratar, lo cual constituye una prioridad de investigación urgente. ${ }^{7}$ Por otro lado, resulta un desafío diagnosticar TB en receptores de órganos trasplantados, al alcanzar un mejor desempeño, el IGRA podría asumir un papel esencial en estas circunstancias. ${ }^{41,42}$

\section{CONCLUSIONES}

Por ser la TB de una enfermedad transmisible con gran distribución internacional y elevada morbimortalidad, resulta imperioso el diagnóstico y tratamiento oportunos de la ITBL para reducir el riesgo de progresión a TBA. ${ }^{14,18}$ Múltiples estudios han demostrado un desempeño superior del IGRA en comparación con la PCT, ya que en esta última existe un mayor riesgo de obtención de resultados falsos positivos por previa vacunación BCG, situación observada en nuestro medio. La prueba IGRA fue diseñada para alcanzar una sensibilidad y especificidad complementarias, lo cual se lleva a cabo al utilizar antígenos específicos frente a MTB ausentes en la vacuna BCG, es decir, ESAT-6, CFP-10 y TB 7.7.,5
No obstante, el IGRA aún es incapaz de discriminar una infección previa o actual por MTB, así como tampoco es posible diferenciar entre ITBL y TBA.

La prueba IGRA consiste en un método ex vivo con la capacidad de detectar una respuesta inmunitaria específica frente a MTB, esto al cuantificar la producción de IFN- $\gamma$ por parte de los linfocitos-T previamente sensibilizados frente a los antígenos en cuestión; una de la desventajas frente a la PCT es su costo elevado. ${ }^{11,12}$

Al presente, se encuentran disponibles en el mercado 2 modalidades distintas del IGRA: QFT-GIT y T-SPOT ${ }^{\circledR}$. $T B$. La prueba IGRA tiene mayor utilidad y eficacia en personas inmunocompetentes, principalmente en sujetos mayores a 5 años de edad e integrados a un medio socioeconómico favorable; por ello, en nuestro país la normatividad actual mantiene el uso de la PCT como prueba de cribado estándar. ${ }^{19,20}$ Uno de los mecanismos que puede incrementar el uso de los IGRA es que, efectivamente, muestre una reducción de las tasas locales de TB, lo cual podría constituir un medio para la obtención del financiamiento requerido.

Empero, la eficacia clínica del IGRA resulta afectada en individuos inmunodeprimidos, en quienes los valores de IFN- $\gamma$ están disminuidos e incluso llegan a ser fluctuantes, por lo cual algunos autores han recomendado el empleo conjunto con la PCT para obtener una sensibilidad diagnóstica sumativa y en caso de ser necesario, iniciar la terapia preventiva adecuada. ${ }^{15,26}$

Además, la inmunosupresión y otros factores, contribuyen a la aparición de resultados indeterminados en la prueba IGRA, lo cual resulta necesario tomar en consideración al momento de interpretar los hallazgos en ciertos subgrupos de población. ${ }^{28-30}$

Varias citocinas están siendo evaluadas como posibles marcadores biológicos en pruebas IGRA de nueva generación, esto con la finalidad de lograr una mejor relación costo-beneficio y un mejor desempeño en el diagnóstico de ITBL, riesgo de progresión y TBA, sobre todo en los grupos más vulnerables. ${ }^{9,38,41}$

\section{REFERENCIAS}

1. Nenadić N, Kirin BK, Letoja IZ, Plavec D, Topić RZ, Dodig $\mathrm{S}$. Serial interferon- $\gamma$ release assay in children with latent tuberculosis infection and children with tuberculosis. Pediatr Pulmonol 2012;47(4):401-408. doi: 10.1002/ ppul.21555.

2. Delgado-Sánchez G, García-García L, Castellanos-Joya $\mathrm{M}$, et al. Association of pulmonary tuberculosis and diabetes in Mexico: Analysis of the National Tuberculosis Registry 2000-2012. PLoS One 2015;10(6):e0129312. doi: 10.1371/journal.pone.0129312.

3. Demlow SE, Oh P, Barry PM. Increased risk of tuberculosis among foreign-born persons with diabetes in 
California, 2010-2012. BMC Public Health 2015;15:263270. doi: 10.1186/s12889-015-1600-1.

4. Bretscher PA. On the mechanism determining the TH1/TH2 phenotype of an immune response, and its pertinence to strategies for the prevention, and treatment, of certain infectious diseases. Scand J Immunol 2014;79(6):361-376. doi: 10.1111/sji.12175.

5. Little KM, Pai M, Dowdy DW. Costs and consequences of using interferon- $\gamma$ release assays for the diagnosis of active tuberculosis in India. PLoS One 2015;10(4):e0124525. doi: 10.1371/journal.pone.0124525

6. Shakak AO, Khalil EA, Musa AM, et al.; Tuberculosis Research Group/Sudan. Prevalence of latent tuberculosis infection in Sudan: a case-control study comparing interferon-gamma release assay and tuberculin skin test. BMC Public Health 2013;13:1128-1138. doi: 10.1186/1471-2458-13-1128.

7. Pollock L, Roy RB, Kampmann B. How to use: interferon- $\gamma$ release assays for tuberculosis. Arch Dis Child 2013;98:99-105.

8. Sester M, van Leth F, Bruchfeld J, et al.; TBNET. Risk assessment of tuberculosis in immunocompromised patients: a TBNET study. Am J Respir Crit Care Med 2014;190(10):1168-1176. doi: 10.1164/rccm.20140509670C.

9. Chee CB, Sester M, Zhang W, Lange C. Diagnosis and treatment of latent infection with Mycobacterium tuberculosis. Respirology 2013;18(2):205-216. doi: 10.1111/ resp.12002.

10. Abubakar I, Stagg HR, Whitworth H, Lalvani A. How should I interpret an interferon-gamma release assay result for tuberculosis infection? Thorax 2013;68(3):298301. doi: 10.1136/thoraxjnl-2013-203247.

11. Bendayan D, Hendler A, Litman K, Polansky V. The role of interferon-gamma release assays in the diagnosis of active tuberculosis. Isr Med Assoc J 2012;14(2):107-110.

12. Park H, Shin JA, Kim HJ, Ahn CM, Chang YS. Whole blood interferon- $\gamma$ release assay is insufficient for the diagnosis of sputum smear negative pulmonary tuberculosis. Yonsei Med J 2014;55(3):725-731. doi: 10.3349/ ymj.2014.55.3.725.

13. Papay $P$, Eser A, Winkler S, et al. Predictors of indeterminate IFN- $\gamma$ release assay in screening for latent TB in inflammatory bowel diseases. Eur J Clin Invest 2011;41(10):1071-1076. doi: 10.1111/j.13652362.2011.02502.x.

14. Denkinger CM, Dheda K, Pai M. Guidelines on interferon- $\gamma$ release assays for tuberculosis infection: concordance, discordance or confusion? Clin Microbiol Infect 2011;17(6):806-814. doi: 10.1111/j.14690691.2011.03555.x.

15. de Souza-Galvão ML, Latorre I, Altet-Gómez N, et al. Correlation between tuberculin skin test and IGRAs with risk factors for the spread of infection in close contacts with sputum smear positive in pulmonary tuberculosis. BMC Infect Dis 2014;14:258-276. doi: 10.1186/14712334-14-258.

16. Pullar ND, Steinum H, Bruun JN, Dyrhol-Riise AM. HIV patients with latent tuberculosis living in a low-endemic country do not develop active disease during a 2 year follow-up; a Norwegian prospective multicenter study. BMC Infect Dis 2014;14:667-683. doi: 10.1186/s12879014-0667-0.

17. Singh M, Saini AG, Anil N, Aggarwal A. Latent tuberculosis in children: diagnosis and management. Indian J Pediatr 2011;78(4):464-468. doi: 10.1007/s12098-010-0295-7.

18. Dagnew AF, Hussein J, Abebe $M$, et al. Diagnosis of latent tuberculosis infection in healthy young adults in a country with high tuberculosis burden and BCG vaccination at birth. BMC Research Notes 2012;5:415-421. doi: 10.1186/1756-0500-5-415.

19. Frieri M, Settipane RA. What every physician should know about rapid diagnosis of Mycobacterium tuberculosis infection in children using interferon-gamma release assays. Allergy Asthma Proc 2012;33(3):215-216. doi: 10.2500/aap.2012.33.3580.

20. Sollai S, Galli L, de Martino M, Chiappini E. Systematic review and meta-analysis on the utility of interferongamma release assays for the diagnosis of Mycobacterium tuberculosis infection in children: a 2013 update. BMC Infect Dis 2014;14 Suppl 1:S6. doi: 10.1186/14712334-14-S1-S6.

21. Kamiya H, Ikushima S, Kondo K, et al. Diagnostic performance of interferon-gamma release assays in elderly populations in comparison with younger populations. J Infect Chemother 2013;19(2):217-222. doi: 10.1007/ s10156-012-0480-x.

22. Carvalho AC, Schumacher RF, Bigoni S, et al. Contact investigation based on serial interferon-gamma release assays (IGRA) in children from the hematology-oncology ward after exposure to a patient with pulmonary tuberculosis. Infection 2013;41(4):827-831. doi: 10.1007/ s15010-013-0450-y.

23. Diel R, Loddenkemper R, Niemann S, Meywald-Walter K, Nienhaus A. Negative and positive predictive value of a whole-blood interferon- $\gamma$ release assay for developing active tuberculosis: an update. Am J Respir Crit Care Med 2011;183(1):88-95. doi: 10.1164/rccm.20100609740C.

24. Lee SW, Lee CT, Yim JJ. Serial interferon-gamma release assays during treatment of active tuberculosis in young adults. BMC Infect Dis 2010;10:300-307. doi: 10.1186/1471-2334-10-300.

25. Redelman-Sidi G, Sepkowitz KA. IFN- $\gamma$ release assays in the diagnosis of latent tuberculosis infection among immunocompromised adults. Am J Respir Crit Care Med 2013;188(4):422-431. doi: 10.1164/rccm.201209-1621Cl.

26. Lahey T, Czechura T, Crabtree S, et al. Greater preexisting interferon- $\gamma$ responses to mycobacterial antigens and lower bacillary load during HIV-associated tuberculosis. J Infect Dis 2013;208(10):1629-1633. doi: 10.1093/infdis/ jit396.

27. Elzi L, Steffen I, Furrer $\mathrm{H}$, et al. Improved sensitivity of an interferon-gamma release assay (T-SPOT.TB ${ }^{\text {TM}}$ ) in combination with tuberculin skin test for the diagnosis of latent tuberculosis in the presence of HIV co-infection. BMC Infect Dis 2011;11:319-327. doi: 10.1186/1471-233411-319. 
28. Aabye MG, Hermansen TS, Ruhwald M, et al. Negative effect of smoking on the performance of the QuantiFERON ${ }^{\circledR}$-TB Gold In-Tube test. BMC Infect Dis 2012;12:379-384. doi: 10.1186/1471-2334-12-379.

29. Banfield S, Pascoe E, Thambiran A, Siafarikas A, Burgner D. Factors associated with the performance of a bloodbased interferon- $\gamma$ release assay in diagnosing tuberculosis. PLoS One 2012;7(6):e38556. doi: 10.1371/journal. pone.0038556

30. Hang NT, Lien LT, Kobayashi N, et al. Analysis of factors lowering sensitivity of interferon- $\gamma$ release assay for tuberculosis. PLoS One 2011;6(8):e23806. doi: 10.1371/ journal.pone.0023806.

31. Fujikawa A, Fujii T, Mimura S, et al. Tuberculosis contact investigation using interferon-gamma release assay with chest $x$-ray and computed tomography. PLoS One 2014;9(1):e85612. doi: 10.1371/journal.pone.0085612.

32. Jurčev-Savičević A, Katalinić-Janković V, Miše K, Gudelj I. The role of interferon-gamma release assay in tuberculosis control. Arh Hig Rada Toksikol 2012;63(81):49-59. doi: 10.2478/10004-1254-63-2012-2134.

33. Lienhardt C, Fielding K, Hane AA, et al. Evaluation of the prognostic value of IFN- $\gamma$ release assay and tuberculin skin test in household contacts of infectious tuberculosis cases in Senegal. PLoS One 2010;5(5):e10508. doi: 10.1371/journal.pone.0010508.

34. Lee SW, Lee SH, Yim JJ. Serial interferon-gamma release assays after chemoprophylaxis in a tuberculosis outbreak cohort. Infection 2012;40(4):431-435. doi: 10.1007/s15010-012-0265-2.

35. Feng $\mathrm{Y}$, Diao N, Shao L, et al. Interferon-gamma release assay performance in pulmonary and extrapulmonary tuberculosis. PLoS One 2012;7(3):e32652. doi: 10.1371/ journal.pone.0032652.

36. Savaj S, Savoj J, Ranjbar M, Sabzghabaei F. Interferongamma release assay agreement with tuberculin skin test in pretransplant screening for latent tuberculosis in a highprevalence country. Iran J Kidney Dis 2014;8(4):329-332.

37. Taki-Eddin L, Monem F. Utility of an interferon-gamma release assay as a potential diagnostic aid for active pulmonary tuberculosis. J Infect Dev Ctries 2012;6(1):67-72.

38. Schablon A, Diel R, Diner G, et al. Specificity of a whole blood IGRA in German nursing students. BMC Infect Dis 2011;11:245-251. doi: 10.1186/1471-2334-11-245.

39. Fan L, Chen Z, Hao XH, Hu ZY, Xiao HP. Interferon-gamma release assays for the diagnosis of extrapulmonary tuberculosis: a systematic review and meta-analysis. FEMS Immunol Med Microbiol 2012;65(3):456-466. doi: 10.1111/j.1574-695X.2012.00972.x.

40. Elfrink F, van den Hoek A, Mensen ME, Sonder GJ. Screening travellers to high-endemic countries for infection with Mycobacterium tuberculosis using interferongamma release assay; a prospective study. BMC Infect Dis 2014;14:515-520. doi: 10.1186/1471-2334-14-515.

41. Tabarsi P, Yousefzadeh A, Najafizadeh K, et al. Performance of QuantiFERON ${ }^{\circledR}$-TB Gold In-Tube test in detecting latent tuberculosis infection in brain-dead organ donors in Iran: a brief report. Saudi J Kidney Dis Transpl 2014;25(6):1240-1243.

42. Mardani M, Farshidpour M, Nekoonam M, et al. Performance of QuantiFERON ${ }^{\circledR}$-TB Gold In-Tube test compared with the tuberculin skin test for detecting latent tuberculosis infection in lung and heart transplant candidates. Exp Clin Transplant 2014;12(2):129-132.

\section{$\triangle$ Correspondencia:}

Dr. Limberth Machado Villarroel

Hospital Ángeles. Av. Campos Elíseos

Núm. 9371, Fracc. Campos Elíseos, 32420, Cd.

Juárez, Chihuahua, México.

Correo Electrónico: limberthmv@hotmail.com

Los autores declaran no tener conflicto de intereses. 